\title{
Insulin Control of Glucose Metabolism in Man
}

\author{
A NEW KINETIC ANALYSIS
}

\author{
Paul A. Insel, John E. Liljenquist, Jordan D. Tobin, Robert S. Sherwin, \\ Paul Watkins, Reubin Andres, and Mones Berman \\ From the Clinical Physiology Branch, Gerontology Research Center, \\ National Institute of Child Health and Human Development, National \\ Institutes of Health, The Baltimore City Hospitals, Baltimore, Maryland \\ 21224, and the Laboratory of Theoretical Biology, National Cancer \\ Institute, National Institutes of Health, Bethesda, Maryland 20014
}

\begin{abstract}
A в S T R A C T Analyses of the control of glucose metabolism by insulin have been hampered by changes in blood glucose concentration induced by insulin administration with resultant activation of hypoglycemic counterregulatory mechanisms. To eliminate such mechanisms, we have employed the glucose clamp technique which allows maintenance of fasting blood glucose concentration during and after the administration of insulin. Analyses of six studies performed in young healthy men in the postabsorptive state utilizing the concurrent administration of $\left[{ }^{14} \mathrm{C}\right]$ glucose and $1 \mathrm{mU} / \mathrm{kg}$ per $\mathrm{min}$ ( $40 \mathrm{mU} / \mathrm{m}^{2}$ per $\mathrm{min}$ ) porcine insulin led to the development of kinetic models for insulin and for glucose. These models account quantitatively for the control of insulin on glucose utilization and on endogenous glucose production during nonsteady states.

The glucose model, a parallel three-compartment model, has a central compartment (mass $=68 \pm 7 \mathrm{mg}$ / $\mathrm{kg}$; space of distribution $=$ blood water volume) in rapid equilibrium with a smaller compartment $(50 \pm 17$ $\mathrm{mg} / \mathrm{kg}$ ) and in slow equilibrium with a larger compartment $(96 \pm 21 \mathrm{mg} / \mathrm{kg}$ ). The total plasma equivalent space for the glucose system averaged 15.8 liters or $20.3 \%$ body weight. Two modes of glucose loss are introduced in the model. One is a zero-order loss (insulin and glucose independent) from blood to the central nervous system; its magnitude was estimated from published data. The other is an insulin-dependent loss, occurring from the rapidly equilibrating compartment and, in the basal period, is smaller than the insulin-independent loss. Endogenous glucose production averaged $1.74 \mathrm{mg} /$ $\mathrm{kg}$ per min in the basal state and enters the central compartment directly.
\end{abstract}

Received for publication 29 March 1974 and in revised form 27 December 1974.
During the glucose clamp experiments plasma insulin levels reached a plateau of $95 \pm 8 \mu \mathrm{U} / \mathrm{ml}$. Over the entire range of insulin levels studied, glucose losses were best correlated with levels of insulin in a slowly equilibrating insulin compartment of a three-compartment insulin model. A proportional control by this compartment on glucose utilization was adequate to satisfy the observed data. Insulin also rapidly decreased the endogenous glucose production to $33 \%$ of its basal level $(0.58 \mathrm{mg} /$ $\mathrm{kg}$ per $\mathrm{min}$ ), this suppression being maintained for at least $40 \mathrm{~min}$ after exogenous insulin infusion was terminated and after plasma insulin concentrations had returned to basal levels.

The change in glucose utilization per unit change in insulin in the slowly equilibrating insulin compartment is proposed as a new measure for insulin sensitivity. This defines insulin effects more precisely than previously used measures, such as plasma glucose/plasma insulin concentration ratios.

Glucose clamp studies and the modeling of the coupled kinetics of glucose and insulin offers a new and potentially valuable tool to the study of altered states of carbohydrate metabolism.

\section{INTRODUCTION}

The maintenance of blood sugar in man is a complex process involving feedback control of insulin on glucose and of glucose on insulin. For example, insulin administration to a person in a postabsorptive state produces hypoglycemia which is followed by counterregulatory mechanisms aimed at raising the decreased blood glucose but which may also affect the secretion of insulin itself. By use of the glucose clamp technique $(1,2)$, the blood glucose concentration is maintained by a feedback-controlled glucose infusion after administra- 
TABLE I

Clinical Characteristics of Subjects

\begin{tabular}{|c|c|c|c|c|c|c|c|c|c|c|}
\hline Subject & Age & Height & Weight & $\begin{array}{c}\text { Surface } \\
\text { area }\end{array}$ & $\begin{array}{l}\text { Lean } \\
\text { body } \\
\text { mass }\end{array}$ & $\begin{array}{l}\text { Body } \\
\text { fat }\end{array}$ & $\begin{array}{c}\text { Obesity } \\
\text { index* }\end{array}$ & $\begin{array}{c}\text { Glucose } \\
\text { tolerance } \\
\text { test } \\
\text { (percentile } \\
\text { rank) }\end{array}$ & $\begin{array}{l}\text { Caloric } \\
\text { intake }\end{array}$ & $\begin{array}{c}\text { Carbo- } \\
\text { hydrate } \\
\text { intake }\end{array}$ \\
\hline & $y r$ & inches & $\mathrm{kg}$ & $m^{2}$ & $\mathrm{~kg}$ & $\%$ body wt & & $\%$ & $c a l / d a y$ & $g / d a y$ \\
\hline R. B. & 18 & 73.4 & 85.4 & 2.09 & 69.3 & 18.9 & 1.12 & 21 & 4,700 & 490 \\
\hline R. D. & 28 & 69.7 & 88.1 & 2.09 & 71.3 & 19.7 & 1.19 & 38 & 3,400 & 460 \\
\hline W. E. & 32 & 68.0 & 79.2 & 1.92 & 62.8 & 20.7 & 1.19 & 32 & 2,400 & 240 \\
\hline W. H. & 24 & 71.5 & 77.6 & 1.97 & 62.4 & 19.6 & 1.06 & 97 & 3,000 & 310 \\
\hline J. R. & 28 & 69.4 & 72.4 & 1.88 & 59.8 & 17.3 & 1.06 & 30 & 3,400 & 300 \\
\hline W. S. & 34 & 68.8 & 69.7 & 1.83 & 59.8 & 14.2 & 1.08 & 78 & 3,300 & 390 \\
\hline Mean & 27.3 & 70.1 & 78.7 & 1.96 & 64.2 & 18.4 & 1.12 & 49.3 & 3,560 & 365 \\
\hline$\pm \mathrm{SD}$ & \pm 5.8 & \pm 2.0 & \pm 7.1 & \pm 0.11 & \pm 4.9 & \pm 2.3 & \pm 0.06 & \pm 30.7 & \pm 660 & \pm 98 \\
\hline
\end{tabular}

* The middle of the weight range for male subjects of medium frame from the 1959 Metropolitan Life Insurance Company table for desirable weight was used for all subjects except R. D. who obviously had a larger frame than the other subjects.

tion of physiologic amounts of insulin, thus preventing the appearance of such counterregulatory variables. The glucose infused to maintain a constant blood glucose is a measure of glucose utilization under such conditions.

Insulin is also known to inhibit endogenous glucose production in experimental animals and in man (3-13). This effect supplements increased peripheral glucose utilization in causing blood glucose concentration to fall. Previous studies with insulin administration have not always differentiated between these two insulin effects.

Analysis of isotope kinetic data involving a combination of tracer and tracee (cold) glucose experiments allows the development of a formal mathematical model in which the various metabolic factors can be imbedded and studied. A number of glucose models have previously been described, some of which include feedback control of insulin on glucose (14-21). These studies did not isolate the individual controls but rather combined the entire system into a simplified glucose-insulin feedback system. By maintaining a constant blood glucose concentration we have disrupted the feedback loop and were thus able to study isolated subsystems.

In these studies, $\left[{ }^{14} \mathrm{C}\right]$ glucose was administered during a glucose clamp experiment. The analysis permitted us to define a three-compartment glucose model to describe the control of insulin on glucose utilization, to quantify changes in endogenous glucose production induced by changes in insulin, and to suggest a new measure of insulin effectiveness in man.

\section{METHODS}

Patient selection and preparation (Table I). Six healthy male volunteers participated in servo-controlled euglycemic studies in which $\left[1-{ }^{14} \mathrm{C}\right]$ glucose was used as a tracer. All were young (18-34 yr) and ambulatory; they were taking no medications, and had negative family histories of diabetes. All subjects consumed weight-maintaining daily diets of at least $2,400 \mathrm{cal}$, including at least $240 \mathrm{~g}$ of carbohydrates $(22,23)$. All subjects were within $20 \%$ of desirable body weight. Anthropometric evaluation by the Behnke method (24) yielded a percent body fat of $18.4 \pm 2.3$ (mean $\pm \mathrm{SD}$ ) with a lean body mass of $64.2 \pm 4.9 \mathrm{~kg}$. All studies were performed in the morning after an overnight fast. Glucose tolerance was normal in each of the subjects as determined by oral administration of $1.75 \mathrm{~g}$ of glucose $/ \mathrm{kg}$ body weight and by using age-adjusted criteria for the interpretation of the test (25). All volunteers were advised of the nature and effects of the study and informed consent was obtained.

Experimental protocol. The basic procedure of the glucose clamp experiment is described elsewhere (2). Antecubital intravenous catheter(s) and a brachial artery catheter were inserted for the intravenous infusion of solutions described below and for the withdrawal of arterial blood samples. A priming injection of $8-20 \mu \mathrm{Ci}$ of $\left[1-{ }^{14} \mathrm{C}\right]$ glucose (New England Nuclear, Boston, Mass., and Amersham/ Searle Corp., Arlington Heights, Ill.) was injected in approximately $1 \mathrm{~min}$ followed by a continuous infusion of radioactive glucose. The ratio of the priming dose (microcuries) to the continuous infusion rate (microcuries per hour) was 2:1. Arterial plasma samples were analyzed every 15-30 $\mathrm{min}$ to determine glucose concentration and radioactivity during the preinsulin infusion period.

After the attainment of a plateau in the ${ }^{14} \mathrm{C}$ specific activity, a priming insulin infusion was given in $10 \mathrm{~min}$, followed by a continuous infusion at a rate of $40 \mathrm{mU} / \mathrm{m}^{2}$ body surface area (or $1 \mathrm{mU} / \mathrm{kg}$ body weight) per min for an additional $70 \mathrm{~min}$ in four subjects, for $110 \mathrm{~min}$ in subject R. D., and for $170 \mathrm{~min}$ in subject R. B. (2). $4 \mathrm{~min}$ after the priming insulin infusion began, a glucose infusion was started to maintain the arterial glucose concentration at or near each subject's fasting level and was continued for 40 min after stopping the insulin infusion. In five of six studies, the specific activity of this infusate was adjusted with [1${ }^{14} \mathrm{C}$ ]glucose to equal the plateau of plasma specific activity. Thus, all subjects received a primed continuous infusion of $\left[1-{ }^{14} \mathrm{C}\right]$ glucose and five of the six subjects received an additional infusion of $\left[1{ }^{14} \mathrm{C}\right]$ glucose with a glucose specific 
activity equal to the previously attained plasma plateau. The sixth volunteer (R. B.) was given a pulse injection of $\left[1-{ }^{14} \mathrm{C}\right]$ glucose followed by a continuous radioactive glucose infusion, which was maintained for $120 \mathrm{~min}$ after the insulin infusion was begun (insulin being given for a total of 180 $\min )$. He received no additional radioactivity in the glucose infusion which was given to maintain glucose at fasting level.

During and after the insulin infusion, arterial blood samples were obtained at 5 -min intervals for rapid determination of blood glucose concentration to adjust the exogenous glucose infusion. Samples at $10-\mathrm{min}$ intervals were later assayed for plasma glucose concentration and radioactivity. Plasma from samples drawn at 5-min intervals was frozen and subsequently analyzed for insulin.

Five of the six volunteers also participated in a second study in which a pulse injection of $\left[1{ }^{14} \mathrm{C}\right]$ glucose was given intravenously after an overnight fast. Arterial blood samples were collected at frequent intervals thereafter. These studies provided additional data for computer modeling.

Chemical analysis. Glucose concentrations were measured by the Technicon AutoAnalyzer (Technicon Instruments Corp., Tarrytown, N. Y.) (ferricyanide reduction) procedure. Plasma was assayed for insulin in duplicate by a modification of the semiautomated double antibody radioimmunoassay technique (26). Plasma was deproteinized by the method of Somogyi (27), and labeled anionic metabolic intermediates were removed by passing the deproteinized samples through columns containing Amberlite MB-3 ion exchange resin, bicarbonate form (Mallinckrodt Chemical Works, St. Louis, Mo.). Eluate radioactivity was determined by dissolving the sample in either Insta-gel (Packard Instrument Co., Inc., Downers Grove, Ill.) or Aquasol (New England Nuclear) and counting in a Packard model 3003 Tri-Carb liquid scintillation spectrometer (78-82\% efficiency) with internal quenching.

Column eluate was then analyzed for $\left[6-{ }^{14} \mathrm{C}\right]$ glucose by the addition of carrier glucose followed by oxidation with periodic acid. Addition of 5,5-dimethyl-1,3-cyclohexanedione (dimedone) selectively precipitated formaldehyde (C6) as the formaldemethone while leaving formic acid $(\mathrm{C} 1-5)$ in solution (28). The precipitate was counted in Insta-gel, in which it was totally soluble. These $\left[{ }^{14} \mathrm{C}\right]$ glucose counts were multiplied by 4 to correct the estimate of $\left[1-{ }^{14} \mathrm{C}\right]$ glucose for recycled glucose.

The chemical purity of the $\left[1-{ }^{14} \mathrm{C}\right]$ glucose was established by thin-layer chromatography in isopropanol:pyridine: water $(7: 7: 2)$ followed by staining and autoradiography; no contaminants (either radioactive or nonradioactive) were found. Isotopic uniformity of the $\left[1{ }^{14} \mathrm{C}\right]$ glucose was determined by analysis for $\left[6-{ }^{14} \mathrm{C}\right]$ glucose as described above. Our results indicate the New England Nuclear product contained $0.22 \%\left[6-{ }^{14} \mathrm{C}\right]$ glucose and the Amersham/Searle product contained $0.55 \%$; these results were incorporated into the analysis of the data.

\section{DATA ANALYSIS}

The data analysis and modeling was performed on a Univac 1108 digital computer (Univac Div., Sperry Rand Corp., Philadelphia, $\mathrm{Pa}$.) using the SAAM25 program (29). All tracer and tracee data (Table II) were employed in the analysis and the method of least squares was used to fit the data. This method permits the quantitative evaluation of multiple parameter models. Although some of the parameters can be determined from specific or limited data (e.g. the pool size of a substance from a dilution curve), most

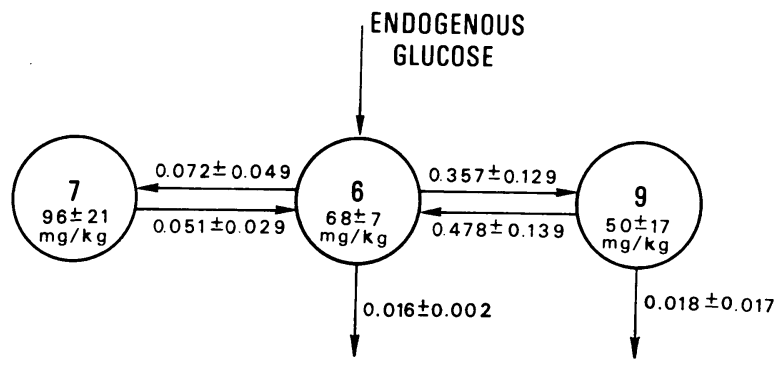

FIGURE 1 The three-compartment basal glucose model with the mean population values for masses and exchange constants $(n=6)$. Rate constants are in units per minute; mean $\pm \mathrm{SD}$.

are derived from all the data considered jointly. This is an automatic feature of the least squares method of data fitting and protects against possible inconsistencies in the analysis.

In this analysis, the radioactivity of $\left[1-{ }^{14} \mathrm{C}\right]$ glucose was corrected for recycled glucose as determined by the dimedone procedure, and arterial glucose concentration in plasma water was utilized for tracee glucose data.

The glucose subsystem for the basal state was determined from the glucose tracer data. A minimal three-compartment model was necessary to fit data for all subjects. A parallel (mammillary) model similar to previously described glucose models $(15-18,20,21)$, was arbitrarily chosen (Fig. 1). Tracer data from the early time period were inadequate to define the initial space of distribution of glucose. Since plasma glucose exchanges rapidly with erythrocytes (30), the estimated blood water volume (31) for each patient was chosen as the initial space of distribution.

To focus more sharply on possible sites of control of insulin on glucose transport and the functional form of that control, we decided to separate losses of glucose that are insulin independent. The major such loss is to the central nervous system $(\mathrm{CNS})^{1}(32-34)$, which probably takes place directly from the plasma compartment. Since CNS loss remains relatively constant over small variations of plasma glucose concentration, it was introduced as a zeroorder process. This could also have been modeled as a first-order process since glucose was maintained close to its basal level. The value assigned to this loss is based on age-interpolated data for similar subjects in the literature (35-37).

With the CNS loss fixed it is still not possible to determine from the basal tracer data alone the compartment from which the remaining loss should take place. The data during insulin infusion were utilized to assist in this decision. The insulin subsystem adopted for these studies (Fig. 2 ) is the three-compartment model previously developed by us (2). In that model changes in the mass of insulin in the slowly equilibrating compartment $3\left(I_{3}\right)$ were temporally associated with changes in the rate of glucose infusion for the maintenance of a constant blood glucose. It was anticipated that $I_{3}$ would control glucose transport from the comparable slow glucose compartment (compartment 7). This, however, proved impossible in subjects having large insulin effects, because the required glucose could not be supplied rapidly enough to this compartment. The loss was there-

${ }^{1}$ Abbreviations used in this paper: CNS, central nervous system; EGP, endogenous glucose production; PEV plasma water equivalent volume. 
TABLE II

Typical Set of Data; Subject J. R.

\begin{tabular}{|c|c|c|c|c|c|c|c|}
\hline \multirow[b]{3}{*}{ Time } & \multirow[b]{3}{*}{$\begin{array}{l}\text { Plasma } \\
\text { insulin }\end{array}$} & \multicolumn{4}{|c|}{ Glucose clamp experiment } & \multirow{2}{*}{\multicolumn{2}{|c|}{ Single injection experiment\| }} \\
\hline & & \multirow{2}{*}{$\begin{array}{c}\text { Plasma } \\
\text { water } \\
\text { glucose } \\
\text { concen- } \\
\text { tration }\end{array}$} & \multirow[b]{2}{*}{$\begin{array}{l}\text { Exogenous } \\
\text { glucose } \\
\text { infusion }\end{array}$} & \multirow{2}{*}{$\begin{array}{l}\text { Plasma } \\
\text { glucose } \\
\text { specific } \\
\text { activity }\end{array}$} & \multirow[b]{2}{*}{$\begin{array}{c}\text { Exogenous } \\
{\left[{ }^{14} \mathrm{C}\right] \text { glucose }} \\
\text { infusion }\end{array}$} & & \\
\hline & & & & & & Time & $\begin{array}{l}\text { Glucose } \\
\text { radio- } \\
\text { activity }\end{array}$ \\
\hline $\min$ & $\mu U / m l$ & $m g / m l$ & $m g / m i n$ & $d p m / m g$ & $d p m / \min \times 10^{5}$ & $\min$ & $d p m / m l$ \\
\hline 0 & & 1.170 & & & $276.68^{*}$ & 1 & 2,511 \\
\hline 5 & & 1.178 & & 2,137 & 2.312 & 1.5 & 2,148 \\
\hline 30 & & 1.096 & & 1,692 & 2.312 & 2 & 2,009 \\
\hline 60 & 7 & 1.087 & & 1,665 & 2.312 & 3 & 1,795 \\
\hline 90 & 8 & 1.055 & & 1,671 & 2.312 & 4 & 1,700 \\
\hline $148 \ddagger$ & 8 & 1.039 & 0 & 1,687 & 2.312 & 5 & 1,549 \\
\hline 153 & 84 & & 144.8 & & 4.837 & 6 & 1,550 \\
\hline 158 & 102 & 1.058 & 205.0 & 1,776 & 5.887 & 8 & 1,618 \\
\hline 163 & 87 & & & & & 10 & 1,232 \\
\hline 168 & 87 & 0.995 & 258.8 & 1,877 & 6.825 & 12.5 & 1,200 \\
\hline 173 & 87 & & & & & 15 & 1,151 \\
\hline 178 & 91 & 0.915 & 348.2 & 1,923 & 8.385 & 20 & 1,006 \\
\hline 183 & 93 & & & & & 25 & 893 \\
\hline 188 & 81 & 0.899 & 411.1 & 1,976 & 9.482 & 30 & 866 \\
\hline 193 & 84 & & & & & 35 & 833 \\
\hline 198 & 102 & 0.917 & 510.7 & 1,997 & 11.219 & 40 & 761 \\
\hline 203 & 87 & & & & & 50 & 696 \\
\hline 208 & 84 & 1.016 & 469.8 & 1,985 & 10.505 & 60 & 644 \\
\hline 213 & 96 & & & & & 90 & 475 \\
\hline 218 & 84 & 0.932 & 523.8 & & 11.447 & 120 & 251 \\
\hline 223 & 90 & & & & & 150 & 289 \\
\hline $228 \S$ & 93 & 1.049 & 517.4 & 2,007 & 11.335 & 180 & 222 \\
\hline 233 & 39 & & & & & & \\
\hline 238 & 25 & 0.998 & 461.7 & 2,059 & 10.469 & & \\
\hline 243 & 17 & & & & & & \\
\hline 248 & 15 & 1.015 & 533.0 & 2,031 & 11.608 & & \\
\hline 253 & 17 & & & & & & \\
\hline 258 & 13 & 1.106 & 444.3 & 2,022 & 10.061 & & \\
\hline 263 & 13 & & & & & & \\
\hline 268 & 12 & 1.154 & 444.3 & 2,039 & & & \\
\hline
\end{tabular}

* Prime injection value.

$\ddagger$ Insulin infusion begun at $148 \mathrm{~min}$.

$\S$ Insulin infusion terminated at $228 \mathrm{~min}$.

II Prime injection value was $200.63 \times 10^{5} \mathrm{dpm}$.

fore assigned to the more rapidly exchanging glucose compartment (compartment 9), and is shown as $L_{00}$ in Fig. 3. The value of $L_{00}$ at basal levels (preinsulin infusion) could be uniquely determined from the glucose tracer data.

To explain quantitatively the control of insulin on glucose, the hypothesis was introduced that a change in glucose loss was proportional to a change in insulin level in compartment 3 (linear control). The rate constant $L_{00}$ was therefore defined as $L_{00}=\alpha+\beta I_{3} . \alpha$ is a first-order insulinindependent glucose loss and can be viewed as a correction of the estimated CNS loss $\left(L_{06}\right)$ or an addition to it. $\beta I_{3}$ is the linear insulin control term. When the insulin subsystem was coupled to the glucose subsystem, all infusions and plasma levels (glucose tracer, glucose tracee, and insulin) were matched simultaneously (Fig. 4). All studies were found to be compatible with the $L_{00}$ path and the linear control function proposed.

Endogenously produced glucose is assumed to enter the system into the blood compartment directly, although entry into any (or all) of the three compartments is also possible.

The total glucose utilization, $R_{g}$, is expressed in the model as

$$
R_{\vartheta}=R_{0}+R_{00}=R_{0}+L_{00} M_{\theta}
$$

where $R_{c}$ is the constant rate of utilization by CNS and $L_{00}$ is the effective rate constant for glucose loss from compartment 9 , expressed as

$$
L_{\infty}=\alpha+\beta I_{3},
$$

1060 Insel, Liljenquist, Tobin, Sherwin, Watkins, Andres, and Berman 
where $\alpha$ is a constant (first order), $\beta$ is the insulin control coefficient, and $I_{3}$ is the amount of insulin in compartment 3 .

The basal value of $L_{\infty}$ for each subject was computed from $\left[{ }^{14} \mathrm{C}\right]$ glucose data obtained in the basal period of two independently performed studies (primed continuous infusion and pulse injection). One subject, R. B., did not have the pulse injection. Letting the superscript $B$ represent basal levels,

$$
L_{09}^{B}=\alpha^{-}+\beta I_{3}^{B} \text {. }
$$

Substituting the value of $\alpha$ from this expression into Eq. 2:

$$
L_{09}=L_{09}{ }^{B}+\beta\left(I_{3}-I_{3}^{B}\right),
$$

and further substitution into Eq. 1 yields

$$
R_{g}=R_{c}+L_{09}{ }^{B} M_{9}+\beta\left(I_{3}-I_{3}^{B}\right) M_{9} .
$$

Under steady-state conditions

$$
M_{9}=\frac{L_{96} M_{6}}{L_{69}+L_{09}}=\frac{L_{96} M_{6}}{L_{69}+L_{09}^{B}+\beta\left(I_{3}-I_{3}^{B}\right)} .
$$

Hence,

$$
\begin{aligned}
R_{g}=R_{c}+\left[L_{09}{ }^{B}+\right. & \left.\beta\left(I_{3}-I_{3}^{B}\right)\right] \\
& \times \frac{L_{96} M_{6}}{L_{69}+L_{09}^{B}+\beta\left(I_{3}-I_{3}^{B}\right)} .
\end{aligned}
$$

Since $R_{\boldsymbol{c}}$ and $\beta$ are constants, the derivative of $R_{\boldsymbol{g}}$ with respect to $I_{\mathrm{a}}\left(\mathrm{d} R_{\mathrm{g}} / \mathrm{d} I_{\mathrm{a}}\right)$ for various steady states is a general measure for insulin sensitivity or effectiveness. Because we have not fully resolved the sites of insulin control in the glucose subsystem, and because the actual value of $\mathrm{d} R_{g} / \mathrm{d} I_{3}$ at basal levels is nearly the same as the value of $\beta$, we presently prefer to use $\mathrm{d} R_{g} / \mathrm{d} I_{3}$ as the measure of insulin sensitivity.

To calculate the nonsteady-state rates of endogenous glucose production, it was necessary to account for the transient changes in glucose utilization induced by insulin. Endogenous glucose production was the amount of glucose input required, allowing for infusion and losses, to satisfy the experimentally observed glucose specific activities.

\section{RESULTS}

The glucose clamp data for nonlabeled glucose and for insulin and the insulin model for these subjects have

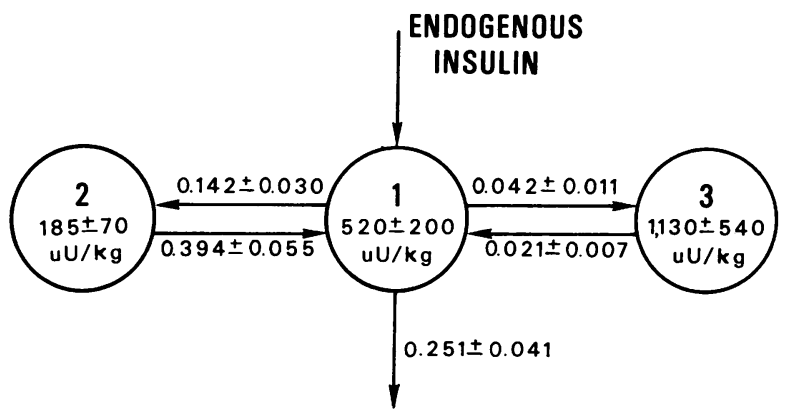

Figure 2 The three compartment basal insulin model with the mean population values for masses and exchange constants $(n=16)(2)$. Rate constants are in units per minute, mean $\pm \mathrm{SD}$.

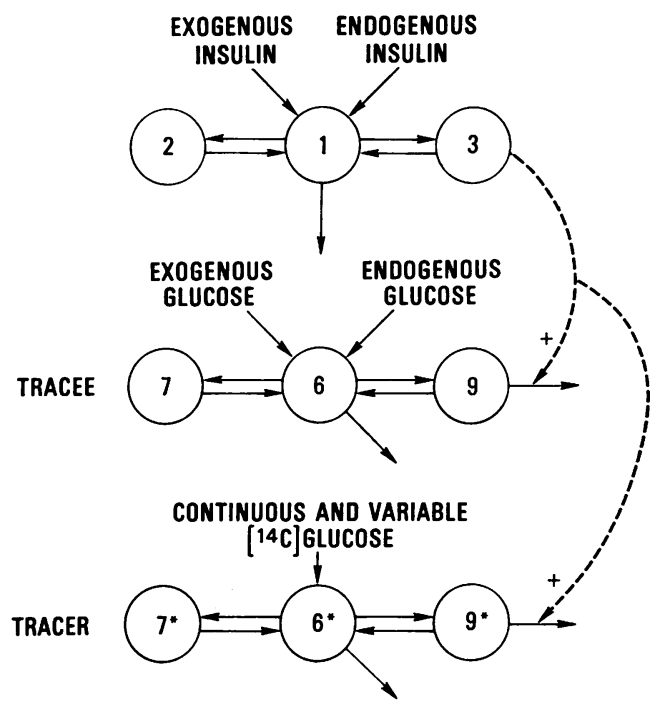

Figure 3 Combined insulin and glucose (tracee and tracer) models. The insulin mass in compartment 3 simultaneously controls the glucose loss from compartment 9 and 9*, the tracee and tracer glucose systems, respectively. This effect is shown by the dotted line and "+" signs on $L_{00}$ and $L_{\infty} *$.

been reported previously (2). In these subjects, during the insulin infusion, the plasma insulin levels averaged $95 \pm 8$ (SD) $\mu \mathrm{U} / \mathrm{ml}$. Basal arterial blood glucose concentrations, $G_{\text {bas, }}$ averaged $90 \mathrm{mg} / 100 \mathrm{ml}$ (range $=82-$ 96). Glucose levels during and after insulin infusion, $G_{\text {ins, }}$ were maintained close to each subject's $\bar{G}_{\text {bas }}$ as shown by the ratio $\bar{G}_{\text {ins }} / \bar{G}_{\text {bas }}$ which averaged 0.99 (range $=0.95-1.02)$. The stability of $G_{\mathrm{ins}}$ is shown by the individual coefficients of variation which averaged $4.1 \%$ ( range $=2.7-5.7 \%$ ).

A set of typical data on a subject and the modelpredicted values are given in Table II and Fig. 4. Fig. 1 presents the glucose model with the mean values for the parameters for all six subjects. The ability of this model to fit the mean ${ }^{11} \mathrm{C}$ data in single infusion and primed continuous infusion studies (before insulin) is demonstrated in Fig. 5. Individual data are given in Table III. Compartment 6, as noted in the Data Analysis section, was set equal to the blood water volume (31). Compartment 6 is in rapid equilibrium with a slightly smaller compartment 9 and in slower equilibrium with a larger compartment 7 .

Fig. 6 relates total glucose utilization to the amount of insulin in compartment 3 in accordance with Eq. 7. These are both model-derived values during the basal state and after insulin administration. Thus, the model allows direct quantification of the previously observed close temporal association between these two variables (2). The slopes of the curves (Table IV) are the sensitivities of glucose utilization to insulin changes in com- 

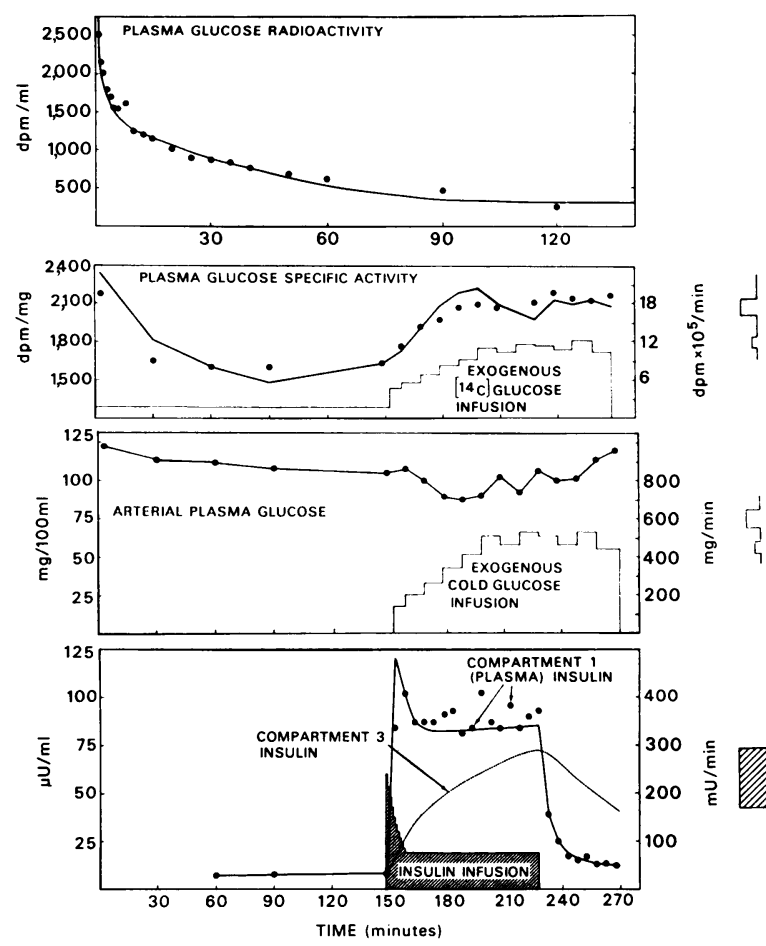

Figure 4 Typical set of data (subject J. R.) used for computer modeling. The actual data are represented as points and computer estimated values by the lines. The top panel shows results of separate single injection study and the lower three panels apply to the clamp experiment. Glucose infusions (tracee and tracer) and the insulin infusion were entered as known information as were the changes in arterial plasma glucose concentration, thus yielding exact computer fitting of these values.

pariment 3 . The sensitivity at basal levels is very close to the maximum sensitivity derived theoretically from Eq. 7. It should be noted, however, that glucose and insulin values only at and above basal levels were available to test the model. Therefore, the use of Eq. 7 for levels below basal is only theoretical, thus the dotted portions of the lines in Fig. 6. The basal slopes demonstrate two negative correlations: $(a)$ with the $y$ intercept $(r=-0.85, P<0.05)$ and $(b)$ with percent body fat in these subjects $(r=-0.95, P<0.01)$.

In the basal period endogenous glucose production (EGP) averaged $140.1 \mathrm{mg} / \mathrm{min}$ or $1.74 \mathrm{mg} / \mathrm{kg}$ per min (Table V). In the five subjects receiving glucose infusions with specific activities matched to the preinsulin infusion values, specific activities rose during the insulin infusions as illustrated by subject J. R. in Table II and Fig. 4. This indicates that EGP fell under the influence of the insulin infused. A diminution to $33 \%$ of the basal level occurred during the insulin infusion (Table V). This level was reached within 10 min and persisted after cessation of the insulin infusion.

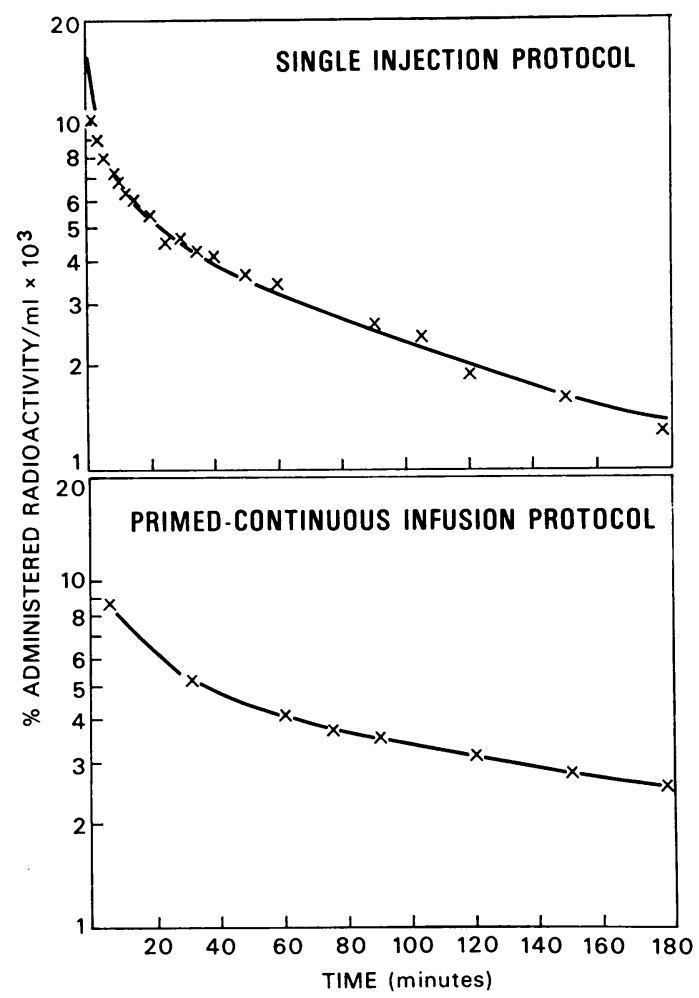

FigURE 5 Simultaneous computer match of mean plasma $\left[{ }^{14} \mathrm{C}\right]$ glucose data for single injection and primed continuous infusion protocols during basal state. " $X$ " are actual data and solid lines represent computer estimated values. Primed continuous infusion protocol demonstrates a falling curve because ordinate expresses percent of the total administered dose still present in plasma at each point in time.

In the basal period EGP matches glucose utilization, since arterial glucose concentration is constant. During insulin infusion, arterial glucose concentration is main-

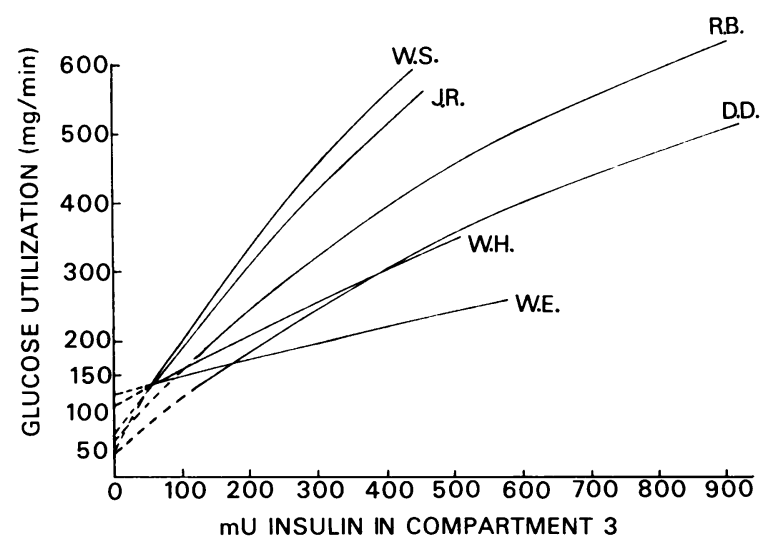

FIgURE 6 Insulin effectiveness. Total glucose utilization (milligrams per minute vs. mass (milliunits) insulin in compartment 3 derived from Eq. 7 for six individuals. Values below basal are represented by dotted lines. 
TABLE III

Glucose Model Parameters

\begin{tabular}{|c|c|c|c|c|c|c|c|c|c|c|c|c|}
\hline \multirow[b]{2}{*}{ Subjects } & \multirow{2}{*}{$\begin{array}{c}\text { Body } \\
\text { weight }\end{array}$} & \multicolumn{6}{|c|}{ Glucose rate constants } & \multicolumn{3}{|c|}{ Glucose masses $\ddagger$} & \multicolumn{2}{|c|}{ Glucose spaces } \\
\hline & & $L_{06}$ & $L_{09}$ & $L_{96}$ & $L_{60}$ & $L_{67}$ & $L_{76}$ & $M_{6}$ & $M_{7}$ & $M 9$ & $V_{6}+V_{7}+V_{98}$ & $V_{6}+V_{7}+V_{9}$ \\
\hline & $\mathrm{kg}$ & $\min ^{-1}$ & $\min ^{-1}$ & $\min ^{-1}$ & $\min ^{-1}$ & $\min ^{-1}$ & $\min ^{-1}$ & $g$ & $g$ & $g$ & liters & liters $/ \mathrm{kg}$ \\
\hline R. B. & 85.4 & 0.014 & $\begin{array}{c}0.052 * \\
(0.016)\end{array}$ & $\begin{array}{c}0.224 \\
(0.071)\end{array}$ & $\begin{array}{c}0.591 \\
(0.165)\end{array}$ & $\begin{array}{c}0.102 \\
(0.012)\end{array}$ & $\begin{array}{c}0.152 \\
(0.020)\end{array}$ & 5.96 & 8.87 & 2.06 & 15.2 & 0.178 \\
\hline R. D. & 88.1 & 0.015 & $\begin{array}{c}0.012 \\
(0.001)\end{array}$ & $\begin{array}{c}0.230 \\
(0.014)\end{array}$ & $\begin{array}{c}0.304 \\
(0.003)\end{array}$ & $\begin{array}{c}0.048 \\
(0.004)\end{array}$ & $\begin{array}{c}0.065 \\
(0.005)\end{array}$ & 5.51 & 7.53 & 4.00 & 16.1 & 0.184 \\
\hline W. E. & 79.2 & 0.014 & $\begin{array}{c}0.019 \\
(0.002)\end{array}$ & $\begin{array}{c}0.282 \\
(0.014)\end{array}$ & $\begin{array}{c}0.536 \\
(0.28)\end{array}$ & $\begin{array}{c}0.043 \\
(0.004)\end{array}$ & $\begin{array}{c}0.042 \\
(0.004)\end{array}$ & 5.80 & 5.64 & 2.94 & 13.4 & 0.170 \\
\hline W. H. & 77.6 & 0.016 & $\begin{array}{c}0.012 \\
(0.002)\end{array}$ & $\begin{array}{c}0.509 \\
(0.077)\end{array}$ & $\begin{array}{c}0.662 \\
(0.134)\end{array}$ & $\begin{array}{c}0.057 \\
(0.009)\end{array}$ & $\begin{array}{c}0.078 \\
(0.014)\end{array}$ & 5.56 & 7.63 & 4.20 & 15.0 & 0.194 \\
\hline J. R. & 72.4 & 0.019 & $\begin{array}{c}0.0063 \\
(0.0021)\end{array}$ & $\begin{array}{c}0.493 \\
(0.073)\end{array}$ & $\begin{array}{c}0.376 \\
(0.080)\end{array}$ & $\begin{array}{c}0.012 \\
(0.010)\end{array}$ & $\begin{array}{c}0.025 \\
(0.006)\end{array}$ & 4.64 & 9.78 & 6.00 & 19.0 & 0.262 \\
\hline W. S. & 69.7 & 0.017 & $\begin{array}{c}0.0092 \\
(0.0016)\end{array}$ & $\begin{array}{c}0.402 \\
(0.016)\end{array}$ & $\begin{array}{c}0.401 \\
(0.012)\end{array}$ & $\begin{array}{c}0.045 \\
(0.003)\end{array}$ & $\begin{array}{c}0.055 \\
(0.003)\end{array}$ & 4.72 & 5.75 & 4.62 & 15.9 & 0.228 \\
\hline $\begin{array}{l}\text { Mean } \\
\pm S D\end{array}$ & $\begin{array}{r}78.7 \\
\pm 7.1\end{array}$ & $\begin{array}{r}0.016 \\
\pm 0.002\end{array}$ & $\begin{array}{r}0.0184 \\
\pm 0.0170\end{array}$ & $\begin{array}{r}0.357 \\
\pm 0.129\end{array}$ & $\begin{array}{r}0.478 \\
\pm 0.139\end{array}$ & $\begin{array}{r}0.051 \\
\pm 0.029\end{array}$ & $\begin{array}{r}0.072 \\
\pm 0.049\end{array}$ & $\begin{array}{r}5.36 \\
\pm 0.56\end{array}$ & $\begin{array}{r}7.53 \\
\pm 1.65\end{array}$ & $\begin{array}{r}3.97 \\
\pm 1.36\end{array}$ & $\begin{array}{r}15.8 \\
\pm 1.8\end{array}$ & $\begin{array}{r}0.203 \\
\pm 0.039\end{array}$ \\
\hline
\end{tabular}

* Mean $\pm(\mathrm{SD})$.

$\ddagger M(j)=$ steady-state mass or total amount of glucose in the basal state in compartment $j$.

$\$$ Total plasma equivalent volume $(V)$ of compartments 6,7 , and 9 .

tained at a constant level by supplementing the reduced EGP with the exogenous glucose infusion $(5.4 \mathrm{mg} / \mathrm{kg}$ per $\min$ in these six subjects). Thus, endogenous production $(0.6 \mathrm{mg} / \mathrm{kg}$ per $\mathrm{min}$ ) accounts for only $10 \%$ of total utilization during this phase of the study.

\section{DISCUSSION}

Any definitive compartmental analysis of a tracer substance depends on the frequency of sampling, the number of compartments sampled, and the adequacy of mixing. Glucose, which distributes rapidly and crosses multiple membranes easily, offers fundamental problems in separating a mixing phase from compartmental distribution. These studies were performed using intravenous glucose administration together with arterial glucose sampling. Nevertheless, early glucose distribution was too rapid to permit the resolution of an initial distribution space and an assumption that it was equal to blood volume (water) was made. Waterhouse and Keilson (38) have studied in detail the initial spaces of distribution of glucose and report a somewhat larger space. The aspect of the model which is of primary interest in this paper is glucose utilization and fortu-

TABLE IV

Insulin Effectiveness

\begin{tabular}{|c|c|c|c|c|c|c|}
\hline Subject & Body fat & $\begin{array}{c}\text { Basal insulin } \\
\text { compartment } 3 \\
I_{\mathbf{3}^{B}}\end{array}$ & $\begin{array}{l}\text { Basal slope } \\
\left(\mathrm{d} R_{g} / \mathrm{d} I_{3}{ }^{B}\right)\end{array}$ & $\begin{array}{c}\text { Extrapolated } \\
R_{\theta} \text { at } 0 \\
\text { insulin }\end{array}$ & $\begin{array}{l}\text { Estimated } \\
\text { CNS } \\
\text { utilization }\end{array}$ & $\begin{array}{l}\text { Saturation } \\
\text { value } \\
\left(L_{96} \times M_{6}\right) *\end{array}$ \\
\hline & $\%$ Body wt & $m U$ & $\begin{array}{c}\mathrm{mg} / \mathrm{min} / \mu U \\
\times 10^{4}\end{array}$ & $m g / \min$ & $m g / m i n$ & $\mathrm{~g} / \min$ \\
\hline R. B. & 18.9 & 128.0 & 11.5 & 53.8 & 82.8 & 1.29 \\
\hline R. D. & 19.7 & 122.0 & 8.5 & 34.9 & 81.4 & 1.26 \\
\hline W. E. & 20.7 & 45.8 & 2.7 & 120.0 & 78.7 & 1.55 \\
\hline W. H. & 19.6 & 53.4 & 5.3 & 104.8 & 83.6 & 2.69 \\
\hline J. R. & 17.3 & 47.7 & 15.1 & 46.7 & 81.4 & 2.13 \\
\hline W. S. & 14.2 & 49.0 & 18.2 & 34.8 & 76.7 & 1.78 \\
\hline Mean & 18.4 & 73.8 & 10.2 & 65.8 & 80.8 & 1.77 \\
\hline$\pm \mathrm{SD}$ & \pm 2.3 & \pm 40.0 & \pm 5.9 & \pm 37.1 & \pm 2.6 & \pm 0.54 \\
\hline
\end{tabular}

* The values for $M_{6}$ used in this calculation were the mean plasma glucose concentration during the clamp study and are slightly different from those in Table IV. 
TABLE $\mathrm{V}$

Endogenous Glucose Production

\begin{tabular}{lrrrrrrrr}
\hline Subject* & \multicolumn{2}{c}{ Basal } & \multicolumn{3}{c}{ Insulin period } & \multicolumn{3}{c}{ Postinsulin period } \\
\hline & $m g / m i n$ & $m g / k g / m i n$ & $m g / m i n$ & $m g / k g / m i n$ & $\%$ basal & $m g / m i n$ & $m g / k g / m i n$ & $\%$ basal \\
R. B. $\ddagger$ & 187.4 & 2.19 & 75.7 & 0.89 & 40.4 & 26.9 & 0.31 & 14.4 \\
R. D. & 130.5 & 1.48 & 45.9 & 0.52 & 35.2 & 25.7 & 0.29 & 19.7 \\
W. E. & 131.2 & 1.66 & 26.3 & 0.33 & 20.0 & 33.4 & 0.42 & 25.5 \\
W. H. & 133.8 & 1.72 & 47.4 & 0.61 & 35.6 & $<1$ & $<1$ & 0 \\
J. R. & 117.8 & 1.63 & 40.7 & 0.56 & 34.6 & 28.9 & 0.40 & 24.5 \\
Mean & 140.1 & 1.74 & 47.2 & 0.58 & 33.2 & 23.1 & 0.28 & 16.8 \\
\pm SD & \pm 27.1 & \pm 0.27 & \pm 18.0 & \pm 0.20 & \pm 7.7 & \pm 13.0 & \pm 0.17 & \pm 10.4 \\
\hline
\end{tabular}

* Subject W. S. had a 75-min insulin period with no postinsulin period and was therefore not included.

$\ddagger 180$-min insulin period.

$\$ 120$-min insulin period.

nately this is relatively invariant with respect to this assumption.

Our rapidly equilibrating glucose compartment 9 is somewhat smaller than compartment 6 and the slowly equilibrating compartment 7 is somewhat larger. Identification of these compartments with anatomical or physiological entities is not possible at present. The total plasma water equivalent volume (PEV) is 15.8 liters or $20.3 \%$ body weight. Since a correction was made in our studies for recycled glucose the glucose model does not reflect equilibration with lactate or other recycled glucose precursors.

The model incorporates insulin-dependent and insulinindependent glucose production and loss sites. This model fits data for both insulin under varying conditions (2) and glucose (tracer and tracee infusions and plasma levels) so as to mathematically describe insulin control on glucose utilization (Eq. 7). This control is exerted by the large slowly equilibrating insulin compartment 3 (mean PEV $=9.2 \%$ body weight) on the smaller rapidly equilibrating glucose compartment 9 (mean $\mathrm{PEV}=4.95 \%$ body weight). Physiologically this implies that certain tissues must have selective permeabilities or affinities for insulin vis-à-vis glucose. In some subjects control of the slower glucose compartment by the slower insulin compartment also fits the data. It is likely that insulin controls glucose transport from both rapid and slow compartments. Our data are only adequate to reject the notion that all control takes place at the slowly exchanging glucose compartment.

The curves relating glucose utilization $\left(R_{0}\right)$ to insulin levels $\left(I_{8}\right)$ contain three main features (Fig. 5): (a) The slope of the curve is a measure of glucose sensitivity to insulin. (b) As insulin levels increase the curves flatten, suggesting that "saturation" occurs. This is due to the limitation in the rate of delivery of glucose from compartment 6 to compartment $9\left(L_{08} M_{6}\right)$ (Table III). (c) The extrapolated intercept for $I_{3}=0$ is a hypothetical measure of glucose utilization "independent" of insulin (Eq. 1). This includes CNS and other tissues.

Considerable variation exists in the values of the basal slope of $R_{g}$ vs. $I_{3}$ (Table IV). In view of the multiple variables involved in this relationship (Eq. 7), such variation is not too surprising. The amount of insulin bound to receptors has not been measured in this study, and that value presumably would be the more basic quantity to relate to glucose utilization. In any event it is reasonable to suggest that some quantitative relation exists between the mass of insulin in compartment 3 of the model and the amount of insulin on membrane receptors.

It is interesting to note that a negative correlation exists between the basal slopes and the intercepts in the curves of Fig. 6. If glucose utilization takes place at insulin-dependent and insulin-independent sites an increase in the number of insulin-dependent sites at the expense of insulin-independent sites could result in an increase in the slope with a corresponding decrease in the intercept.

The observed high correlation of the basal slopes with percent body fat reflects the well-known decrease in insulin sensitivity with increase in adiposity. The correlation is all the more remarkable since gross obesity was not being studied; these subjects had amounts of body fat (Table I) which, although variable, are generally considered to be within the limits of normality. More subjects with a wider variability in body fat should be studied to extend this observation.

EGP under basal conditions has been estimated by tracer techniques and by transhepatic catheterization studies $(4,5,8-13,39-41)$. Studies on the effect of insulin on glucose production have been complicated (a) by hypoglycemia and release of counterregulatory hormones when exogenous insulin has been administered or $(b)$ by hyperglycemia when glucose has been

1064 Insel, Lilienquist, Tobin, Sherwin, Watkins, Andres, and Berman 
administered as a stimulus to endogenous insulin release. This study then is the first to examine the effect of insulin in man without these complicating factors.

The rapidity of the fall in EGP with insulin administration suggests that this effect is mediated by insulin in the plasma, compartment 1 , or in the rapidly equilibrating compartment 2 . The fact that suppression of glucose production was not complete (Table IV) suggests either the existence of an insulin-independent fraction of glucose production or that the dose of insulin in these studies was too low to achieve maximum effect. The persistence of the suppression after discontinuing the insulin infusion may be due to persistence of induced enzymes (42-44) or of membrane-bound insulin $(45-48)$.

Tissue sensitivity to insulin can be estimated by several methods. The traditional clinical test has been the single pulse intravenous insulin tolerance test. Since the induced hypoglycemia of this test leads to complex counterregulatory processes, the resultant falling glucose curve is a reflection of the interactions among multiple hormones. A new approach for estimating insulin sensitivity ("glucose impedance") has recently been introduced (49). It requires the simultaneous administration of glucose, insulin, epinephrine, and propranolol. The resultant hyperglycemia at the end of the infusion period is the variable which is used as the measure of sensitivity to the infused insulin. In contrast, the clamp technique with kinetic modeling takes into account individual variability in insulin distribution and metabolism and the temporal relationships of insulin (both plasma and extravascular) to glucose over a range of insulin concentrations.

We have previously (2) discussed the limitation of the use of plasma glucose and insulin concentrations $(G / I$ ratio) to explain hormone-substrate interaction. These studies extend that view by introducing a measure of insulin sensitivity $\left(\mathrm{d} R_{g} / \mathrm{d} I_{3}\right)$ which temporally relates insulin level in an "active" compartment directly to glucose utilization as opposed to plasma glucose levels.

However, to examine the broader interactions between insulin and glucose a quantification of the control of glucose on insulin secretion is required. Hyperglycemic glucose clamp experiments offer a unique tool for such studies. Such data should permit the description of the complete glucose-insulin feedback loop.

\section{ACKNOWLEDGMENTS}

We wish to thank Ms. Mary E. Bannon for her technical assistance, Ms. Annette L. Watts and Ms. Sue Smith for their typing, and Ms. Marjory Weiss for her advice and assistance in the use of the SAAM computer program.

\section{REFERENCES}

1. Andres, R., R. S. Swerdloff, T. Pozefsky, and D. Coleman. 1966. Manual feedback technique for control of blood glucose concentration. In Automation in Analytical Chemistry. L. T. Skeggs, Jr., editor. Mediad, Inc., New York. 486-491.

2. Sherwin, R. S., K. J. Kramer, J. D. Tobin, P. A. Insel, J. E. Liljenquist, M. Berman, and R. Andres. 1974. A model of the kinetics of insulin in man. J. Clin. Invest. 53 : 1481-1492.

3. Mortimore, G. E. 1972. Influence of insulin on hepatic uptake and release of glucose and amino acids. Handb. Physiol. 1.(Sect. 7) : 495-504.

4. de Bodo, R. C., R. Steele, N. Altszuler, A. Dunn, and J. S. Bishop. 1963. On the hormonal regulation of carbohydrate metabolism. Studies with $\mathrm{C}^{14}$ glucose. Recent Prog. Horm. Res. 19 : 445-482.

5. Steele, R., J. S. Bishop, A. Dunn, N. Altszuler, I. Rathgeb, and R. C. de Bodo. 1965. Inhibition by insulin of hepatic glucose production in the normal dog. $\mathrm{Am}$. J. Physiol. 208: 301-306.

6. Mortimore, G. E. 1963. Effect of insulin on release of glucose and urea by isolated rat liver. Am. J. Physiol. 204 : 699-704.

7. Mortimore, G. E., F. King, Jr., L. E. Mondon, and W. H. Glinsmann. 1967. Effects of insulin on net carbohydrate alteration in perfused rat liver. Am. J. Physiol. 212: 179-183.

8. Madison, L. L., B. Combes, R. Adams, and W. Strickland. 1960. The physiological significance of the secretion of endogenous insulin into the portal circulation. III. Evidence for a direct immediate effect of insulin on the balance of glucose across the liver. J. Clin. Invest. 39: 507-522.

9. Searle, G. C., G. E. Mortimore, R. E. Buckley, and W. A. Reilly. 1959. Plasma glucose turnover in humans as studied with $\mathrm{C}^{14}$ glucose. Influence of insulin and tolbutamide. Diabetes. 8: 163-173.

10. Hetenyi, G. 1971. The regulation of glucose production and utilization in the intact animal. Acta Diabetol. Lat. 8: 213-227.

11. Reichard, G. A., A. G. Jacobs, P. Kimbel, N. J. Hochella, and S. Weinhouse. 1960. Effects of insulin on blood glucose entry and removal rates in man. Diabetes. 9: 447-453

12. Hetenyi, G. J., G. A. Wrenshall, and C. H. Best. 1961. Rates of production, utilization, accumulation and apparent distribution spaces of glucose. Diabetes. 10: 304 311.

13. Leonards, J. R., B. R. Landau, J. W. Craig, F. I. R. Martin, M. Miller, and F. M. Barry. 1961. Regulation of blood glucose concentration: hepatic action of insulin. Am. J. Physiol. 201 : 47-54.

14. Segre, G., G. L. Turco, and G. Vercellone. 1973. Modeling blood glucose and insulin kinetics in normal, diabetic, and obese subjects. Diabetes. 22: 94-103.

15. Atkins, G. L. 1971. Investigation of some theoretical models relating the concentration of glucose and insulin in plasma. J. Theor. Biol. 32: 471-494.

16. Norwich, K. H. 1969. Mathematical models of the kinetics of glucose and insulin in plasma. Bull. Math. Biophys. 31 : 105-121.

17. Segal, S., M. Berman, and A. Blair. 1961. The metabolism of $\mathrm{C}^{\mathbf{1}}$-labelled glucose in man and an estimation of the extent of glucose metabolism by the hexose monophosphate pathway. J. Clin. Invest. 40: 1263-1279.

Insulin Control of Glucose in Man 
18. Long, C. L., J. L. Spencer, J. M. Kinney, and J. W. Geiger. 1971. Carbohydrate metabolism in normal man and effect of glucose infusion. J. Appl. Physiol. 31: 102-109.

19. Gatewood, L. C., E. Ackerman, J. W. Rosevear, and G. D. Molnar. 1970. Modelling blood glucose dynamics. Behav. Sci. 15: 72-87.

20. Baker, N., R. A. Shipley, R. E. Clark, and G. E. Incefy. 1959. $C^{14}$ studies in carbohydrate metabolism: glucose pool size and rate of turnover in the normal rat. $\mathrm{Am}$. J. Physiol. 196: 245-252.

21. Kronfeld, D. S., C. F. Ramberg, Jr., and D. M. Shames. 1971. Multicompartmental analysis of glucose kinetics in normal and hypoglycemic cows. Am. J. Physiol. 220: 886-893.

22. Buche, B. D. 1947. The dietary history as a tool in research. J. Am. Diet. Assoc. 23: 1041.

23. Watt, B. K., and A. L. Merrill. 1963. Composition of Food: Raw, Processed, Prepared. U. S. Drug Administration Handbook No. 8. U. S. Government printing Office, Washington, D. C. 190 pp.

24. Behnke, A. R. 1961. Anthropometric fractionation. $J$. Physiol. (Lond.). 16: 949-954.

25. Andres, R. 1971. Aging and diabetes. Med. Clin. North Am. 55: 835-846.

26. Haas, M. L., L. Shenkman, P. Weissman, and R. Andres. 1970. A semiautomated technique for radioimmunoassay. Double antibody assay of insulin. Diabetes. 19: 127-131.

27. Somogyi, M. 1945. Determination of blood sugar. $J$. Biol. Chem. 60: 69-73.

28. Dunn, D. F., B. Friedman, A. R. Maass, G. A. Reichard, and S. Weinhouse. 1957. Effects of insulin on blood glucose entry and removal rates in normal dogs. J. Biol. Chem. 225: 225-237.

29. Berman, M., and M. Weiss. 1967. SAAM Manual. U. S. Public Health Service, Publication No. 1703. U. S. Government Printing Office, Washington, D. C. 200 pp.

30. Britton, H. G. 1964. Permeability of the human red cell to labelled glucose. J. Physiol. (Lond.). 170: 1-20.

31. Hidalgo, V., S. B. Nadler, and T. Block. 1962. The use of the electronic digital computer to determine the best fit of blood volume formulas. J. Nucl. Med. 3: 94 99.

32. Betz, A. L., D. D. Gilboe, D. C. Yudilevich, and C. R. Drewes. 1973. Kinetics of unidirectional glucose transport into the isolated dog brain. Am. J. Physiol. 225 : 586-592.

33. Buschiazzo, P. M., E. B. Terrell, and D. M. Regen 1970. Sugar transport across the blood-brain barrier. Am. J. Physiol. 219: 1505-1513.

34. Paris, C. R., L. H. Johnson, J. H. Wright, Jr., and H. Batsel. 1957. Effect of insulin on transport of several hexoses and pentoses into cells of muscle and brain Am. J. Physiol. 191 : 13-18.
35. Dastur, D. K., M. H. Lane, D. B. Hansen, S. S. Kety, R. Butler, S. Perlin, and L. Sokoloff. 1964. Effects of aging on cerebral circulation and metabolism in man. In Human Aging, J. E. Birren, R. N. Butler, S. W. Greenhouse, L. Sokoloff, and M. R. Yarrow, editors. U. S. Public Health Service Publication No. 986. U. S. Government Printing Office, Washington, D. C. 59-76.

36. Scheinberg, P., and E. A. Stead, Jr. 1949. The cerebral blood flow in male subjects as measured by the nitrous oxide technique. Normal values for blood flow, oxygen utilization, glucose utilization, and peripheral resistance, with observations on the effect of tilting and anxiety. J. Clin. Invest. 28: 1163-1171.

37. Shafer, E. A., J. Symington, and T. Bryce. 1908. Quain's Elements of Anatomy. Longman Group Ltd., London. $342 \mathrm{pp}$.

38. Waterhouse, C., and J. Keilson. 1972. Transfer times across the human body. Bull. Math. Biophys. 34: 33-44.

39. Myers, J. D. 1950. Net splanchnic glucose production in normal man and in various disease states. J. Clin. Invest. 29 : 1421-1429.

40. Bearn, A. G., B. H. Billing, and S. Sherlock. 1952. The response of the liver to insulin in normal subjects and in diabetes mellitus. Hepatic vein catheterisation studies. Clin. Sci. (Oxf.). 11: 151.

41. Felig, P., and J. Wahren. 1971. Influence of endogenous insulin secretion on splanchnic glucose and amino acid metabolism in man. J. Clin. Invest. 50: 1702-1711.

42. Segal, H. L. 1973. Enzymatic interconversion of active and inactive forms of enzymes. Science (Wash. D. C.). $180: 25-32$.

43. Bishop, J. S, and J. Larner 1967. Rapid activationinactivation of liver uridine diphosphate glucose-glycogen transferase and phosphorylase by insulin and glucagon in vivo. J. Biol. Chem. 242: 1354-1356

44. Nuttall, F. Q. 1972. Mechanism of insulin action on glycogen synthesis. Handb. Physiol. 1(Sect. 7) : 395-413.

45. Freychet, P., J. Roth, and D. M. Neville, Jr. 1971. Insulin receptor in the liver: specific binding of ${ }^{125} \mathrm{I}$ insulin to the plasma membrane and its relation to insulin bioactivity. Proc. Natl. Acad. Sci. U. S. A. 68: 18331837.

46. Kahn, R., P. Freychet, D. M. Neville, Jr., and J. Roth. 1972. Quantitative aspects of insulin interaction with liver membranes. Diabetes. 21: 334-335. (Abstr.)

47. de Meyts, P., J. Roth, D. M. Neville, Jr., J. R. Gavin, III, and M. A. Lesniak. 1973. Insulin interactions with its receptors: experimental evidence for negative cooperativity. Biochem. Biophys. Res. Commun. 55: 154161.

48. Cuatrecases, P., B. Desbuquois, and F. Krug. 1971. Insulin-receptor interactions in liver cell membranes. Biochem. Biophys. Res. Commun. 44: 333-339.

49. Shen, S-W., G. S. Reaven, and J. W. Farquhar. 1970. Comparison of impedance to insulin-mediated glucose uptake in normal subjects and in subjects with latent diabetes. J. Clin. Invest. 49: 2151-2160. 